Article

\title{
Synthesis of Novel $\pi$-Conjugated Rod-Rod-Rod Triblock Copolymers Containing Poly(3-hexylthiophene) and Polyacetylene Segments by Combination of Quasi-Living GRIM and Living Anionic Polymerization
}

\section{Tomoya Higashihara ${ }^{1,2}, *$, Cheng-Liang Liu ${ }^{3}$, Wen-Chang Chen ${ }^{4,5}$ and Mitsuru Ueda ${ }^{1}$}

1 Department of Organic and Polymeric Materials, Graduate School of Science and Engineering, Tokyo Institute of Technology, 2-12-1-H-120, O-okayama, Meguro-Ku, Tokyo, 152-8552, Japan; E-Mail: mueda@polymer.titech.ac.jp

2 PRESTO, Japan Science and Technology Agency (JST), 4-1-8, Honcho, Kawaguchi, Saitama 332-0012, Japan

3 Department of Organic Device Engineering, Yamagata University, Yonezawa, Yamagata, 992-8510 Japan; E-Mail: clliu@yz.yamagata-u.ac.jp

4 Department of Chemical Engineering, National Taiwan University, Taipei 106, Taiwan; E-Mail: chenwc@ntu.edu.tw

5 Institute of Polymer Science and Engineering, National Taiwan University, Taipei 106, Taiwan

* Author to whom correspondence should be addressed; E-Mail: thigashihara@ polymer.titech.ac.jp; Tel.: +81-3-5734-2126; Fax: +81-5734-2126.

Received: 17 November 2010; in revised form: 17 December 2010 / Accepted: 6 January 2011 / Published: 10 January 2011

Abstract: The first successful synthesis of a new rod-rod-rod triblock copolymer, polyacetylene(PA)- $b$-poly(3-hexylthiophene)(P3HT)- $b$-PA could be synthesized by a combination of quasi-living Grignard metathesis (GRIM) and living anionic polymerization. We first confirmed that poly(4-tolyl vinyl sulfoxide) (PTVS), which is a soluble precursor for PA, could be synthesized by living anionic polymerization in THF at $-78{ }^{\circ} \mathrm{C}$, initiated with 3-methyl-1,1-diphenylpentyllithium as the initiator in the presence of in situ-generated lithium enolate. The molecular weights (MWs) and polydispersities (PDIs) were well controlled (MW $=5,200-27,000$, PDI $=1.10-1.22$ ), respectively. A coil-rod-coil triblock copolymer, PTVS- $b$-P3HT- $b$-PTVS, (6,000-12,500-6,000) could also be synthesized, initiated with a P3HT-based difunctional macroinitiator in the presence of lithium enolate. GPC-RALLS and ${ }^{1} \mathrm{H}$ NMR analyses confirmed a high degree of structural homogeneity of PTVS- $b$-P3HT- $b$-PTVS. A thermal transformation reaction of the polymer 
was carried out in the film state at $170{ }^{\circ} \mathrm{C}$ for $2 \mathrm{~h}$ to afford PA- $b$-P3HT- $b$-PA quantitatively, as monitored by TGA and FT-IR analyses. The optical and electronic properties as well as the morphological behavior of the block copolymers were investigated by UV-vis spectroscopy, conductivity measurement, and AFM observation.

Keywords: $\pi$-conjugated; poly(3-hexylthiophene); polyacetylene; GRIM polymerization; anionic polymerization

\section{Introduction}

Much attention has recently been paid to block copolymers (BCP)s containing $\pi$-conjugated stiff-rod segments, because of their unique self-assembled structures in addition to their optical and electronic properties [1,2]. Many potential applications utilizing such materials include batteries, capacitors, light-emitting diodes, transistors, photovoltaics, and so on, by exploiting their functionality. Among them, regioregular P3HT has so far been the best class of balanced high-performance materials as $p$-type semiconductors in terms of solubility, chemical stability, charge mobility, and commercial availability [3-6]. A well-defined BCP with a P3HT segment, PS- $b$-oligothiophene(11-mer)- $b$-PS, was first prepared by a combination of living anionic polymerization and stepwise organic synthesis by Hempenius et al. [7]. Since McCullough et al. discovered the quasi-living Grignard metathesis (GRIM) polymerization system for regioregular P3HT [8], followed by the improvement by Yokozawa et al. [9], various BCPs containing P3HT segments have been synthesized [10-52].

Although there are many examples of rod-coil P3HT-based BCPs [10-40], all conjugated rod-rod P3HT-based BCPs [41-52] are still less focused on and limited only to diblock copolythiophene derivatives, regardless of the expectation of high performance as semiconductors, due to the absence of insulating coil segments. Two exceptional examples of well-defined all conjugated rod-rod BCPs, P3HT-b-poly(2,6-dialkoxyphenylene) [53] and P3HT-b-poly(9,9-dioctylfluorene) [54], were very recently synthesized, comprised of different conjugated backbone structures, based on sequential quasi-living GRIM polymerization. However, these counter blocks, polyphenylenes and polyfluorenes, have large bandgaps and are not suited especially for solar cell application. In addition, the introduction of insulating long alkyl segments should be minimized to maintain charge mobility and conductivity.

Polyacetylene (PA) is the simplest conjugated hydrocarbon polymer without side chains, showing helical rod-like structures [55-57]. It normally displays low bandgaps and high conductivity, particularly after doping [55]. Although PA itself is insoluble, the thermal transformation approach from soluble precursory polymers makes it possible to form a homogeneous PA film obtained by solution casting. Hogen-Esch et al. successfully synthesized well-defined PA by the living anionic polymerization of phenyl vinyl sulfoxide, followed by thermal elimination of sulfenic acid from poly(phenyl vinyl sulfoxide) [58]. They also prepared PA- $b$-polystyrene (PS) and PA- $b$-PS- $b$-PA by a sequential living anionic polymerization technique. Hirao et al. applied this living system to prepare more complex BCPs and star polymers containing PA segments using precursory PTVS [59,60]. 
In the course of our study, a facile synthetic method has been developed by a combination of quasi-living GRIM and living anionic polymerization, to synthesize a variety of P3HT-based coil-rod-coil triblock copolymers containing PS, poly(4-vinyltriphenylamine), or PMMA as outer coil segments [16-18]. In the synthesis of PMMA- $b$-P3HT- $b$-PMMA [17], we found that an $\alpha, \omega$-difunctional P3HT macroinitiator with a 1,1-diphenylethylene (DPE) anion is efficient for the living anionic polymerization of MMA (Scheme 1). Since a DPE anion can also initiate the living polymerization of tolyl vinyl sulfoxide (TVS) [59,60], well-defined rod-rod-rod PA- $b$-P3HT- $b$-PA triblock copolymers may possibly be synthesized by using the $\alpha, \omega$-difunctional P3HT macroinitiator for TVS polymerization, followed by thermal transformation (Scheme 2).

Scheme 1. Synthetic routes for PMMA- $b$-P3HT- $b$-PMMA using an $\alpha, \omega$-difunctional P3HT macroinitiator.
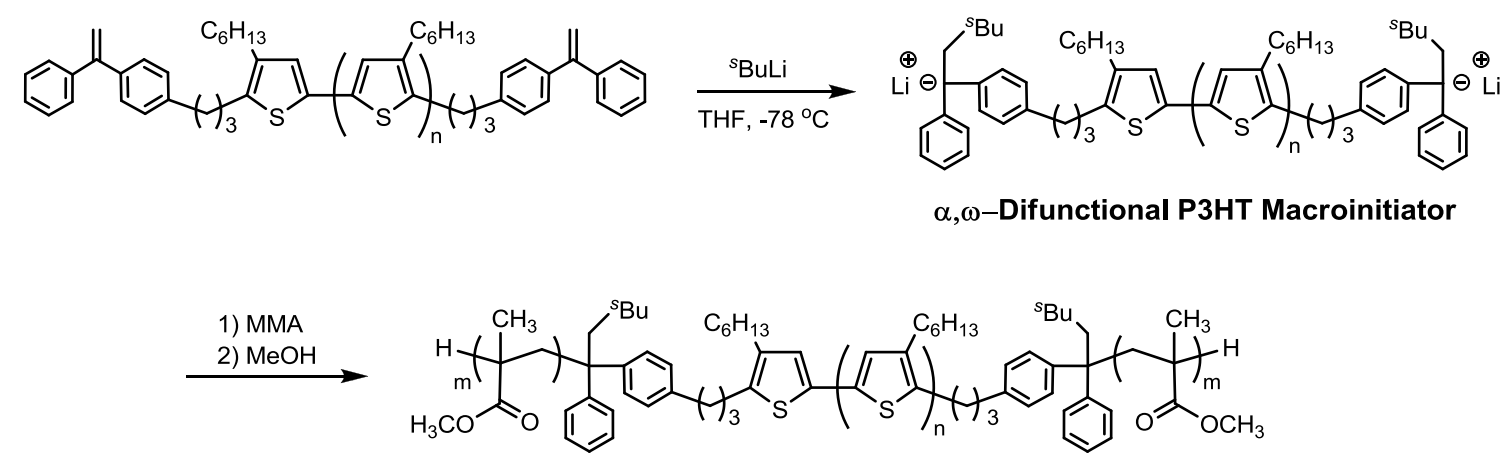

PMMA-b-P3HT-b-PMMA

Scheme 2. Synthetic routes for PA- $b$-P3HT- $b$-PA using an $\alpha, \omega$-difunctional P3HT macroinitiator.

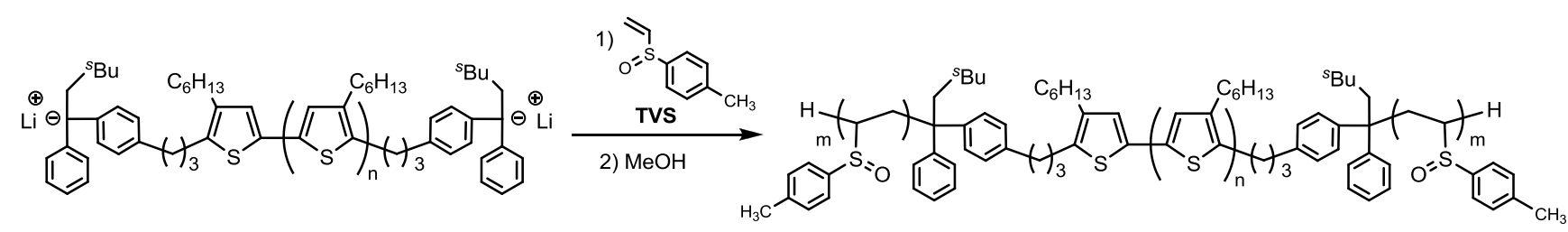

$\alpha, \omega$-Difunctional P3HT Macroinitiator

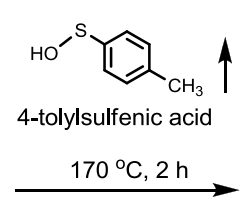

PTVS-b-P3HT-b-PTVS

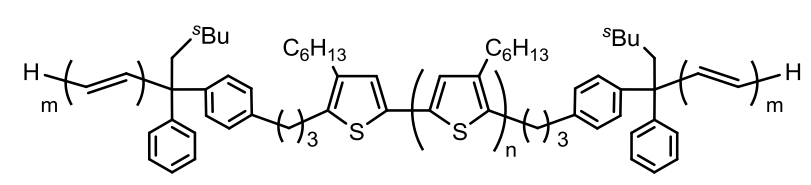

PA-b-P3HT-b-PA

Herein we describe the first successful synthesis of PA- $b$-P3HT- $b$-PA which has never been reported before, by a combination of quasi-living GRIM and living anionic polymerization based on DPE chemistry. The combination of P3HT and PA segments is intriguing because of the attractive features of the PA counter block, such as the absence of insulating side chains, high conductivity, and efficient light harvesting. The formation of self-assembling nanostructures of PA- $b$-P3HT- $b-\mathrm{PA}$ and the possible creation of nanoporous films are also described. 


\section{Experimental Section}

\subsection{Materials}

All reagents were purchased from Sigma-Aldrich Corp. (>99\%) and used as received unless otherwise stated. Tetrahydrofuran (THF, 99.5\%, Wako Chemicals Co., Ltd.) was refluxed over sodium benzophenone under nitrogen for $2 \mathrm{~h}$, then distilled just before use. THF for the solvent of living anionic polymerization was refluxed over $\mathrm{Na}$ wire, then distilled from lithium aluminum hydride. It was finally distilled from sodium naphthalenide on a high vacuum line. 1,1-Diphenylethylene (DPE) was distilled from calcium hydride and 1,1-diphenylhexylthium under reduced pressure. $\alpha, \omega$-DPE difunctional P3HT (DPE-P3HT-DPE) [16] and TVS [59] were synthesized and purified according to the previous papers.

\subsection{Living Anionic Polymerization of TVS}

Living anionic polymerization of TVS was performed by using a standard high vacuum technique. In a typical experiment, $s e c$-BuLi $(2.0 \mathrm{mmol})$ was added to a THF solution $(5.0 \mathrm{~mL})$ of DPE $(0.100 \mathrm{mmol})$ at $-78{ }^{\circ} \mathrm{C}$, and the solution was warmed to room temperature and kept for $1 \mathrm{~h}$. After the solution was again cooled to $-78{ }^{\circ} \mathrm{C}$, a THF solution of TVS $(0.50 \mathrm{~g}, 3.0 \mathrm{mmol})$ was added with vigorous stirring. After $8 \mathrm{~h}$, the solution was poured into a mixture of methanol/water $(90 \mathrm{~mL} / 10 \mathrm{~mL})$ to precipitate the polymer. The polymer was purified by reprecipitation using THF and methanol/water, followed by freeze-drying from its absolute benzene solution to afford PTVS as a white solid (0.48 g, 92\%).

\subsection{Synthesis of PTVS-b-P3HT-b-PTVS}

PTVS- $b$-P3HT- $b$-PTVS was synthesized by using a standard high vacuum technique. To a THF solution $(50.0 \mathrm{~mL})$ of DPE-P3HT-DPE $\left(M_{\mathrm{n}}=12,500\right.$, PDI $=1.10$, r.r. $\left.=97 \%, 0.100 \mathrm{~g}, 0.008 \mathrm{mmol}\right)$ sec-BuLi $(0.320 \mathrm{mmol})$ was added at $-78{ }^{\circ} \mathrm{C}$, and the solution was warmed to room temperature and kept for $1 \mathrm{~h}$. After the solution was cooled to $-78{ }^{\circ} \mathrm{C}$, a THF solution of TVS $(0.628 \mathrm{mmol})$ was added with vigorous stirring. After $24 \mathrm{~h}$, the solution was poured into a mixture of methanol/water $(90 \mathrm{~mL} / 10 \mathrm{~mL})$ to precipitate the polymer. The polymer was purified by fractional precipitation using ethyl acetate, followed by freeze-drying from its absolute benzene solution to afford PTVS- $b$-P3HT- $b$-PTVS as a purple solid $(0.120 \mathrm{~g}, 61 \%)$.

\subsection{Synthesis of PA-b-P3HT-b-PA}

PTVS- $b$-P3HT- $b$-PTVS (1.0 $\mu \mathrm{m}$ thickness) was obtained by spin coating from a chloroform solution $(10 \mathrm{mg} / \mathrm{mL})$ onto a glass substrate. The film was dried under vacuum and then heated at $170{ }^{\circ} \mathrm{C}$ for $2 \mathrm{~h}$. After cooling down to room temperature and purging with nitrogen, a dark purple PA- $b$-P3HT- $b$-PA film was obtained.

\subsection{Measurements}

Molecular weights (MWs) and polydispersity indices (PDIs) were measured with a HPLC system equipped with a pump, refractometer (RI), absorbance detector (UV, $\lambda=254 \mathrm{~nm}$ ), online RALLS 
detector $(\lambda=670 \mathrm{~nm})$, sample processor, and polystyrene gel columns connected in the following series: 650,200 , and $75 \AA$. THF was used as a carrier solvent at a flow rate of $1.0 \mathrm{~mL} / \mathrm{min}$ at room temperature. ${ }^{1} \mathrm{H}$ NMR was recorded on a Bruker DPX (300 MHz) in chloroform- $d$ calibrated to tetramethylsilane as an internal standard $(\delta \mathrm{H} 0.00)$. TGA was performed on a Seiko EXSTAR 6000 TG/DTA 6300 thermal analyzer at a heating rate of $10{ }^{\circ} \mathrm{C} / \mathrm{min}$. FT-IR spectra were measured by a Horiba FT-120 Fourier transform spectrophotometer. UV-vis absorption spectra of a polymer solution in chloroform and the thin film were recorded on a Jasco FP-750 spectrometer over a wavelength range of 250-800 $\mathrm{nm}$. The films were obtained by spin coating from a toluene solution, followed by drying under vacuum. AFM phase images were taken with a SII-NT SPA 400 operating in a tapping mode. Electric conductivity was measured by the typical four point probe technique using a cast film from a toluene solution $(5 \mathrm{mg} / \mathrm{mL})$ onto a glass substrate.

\section{Results and Discussion}

\subsection{Living Anionic Polymerization of TVS}

As mentioned in the Introduction, Hogen-Esch et al. demonstrated that the polymerization of phenyl vinyl sulfoxide proceeded in a living manner to afford polymers with controlled MWs and relatively low PDIs in the range of 1.2 to 1.4 [58]. They also succeeded in a quantitative transformation reaction into PA simply by thermal treatment. By this success, poly(phenyl vinyl sulfoxide) obtained by living anionic polymerization becomes an advantageous PA precursor, soluble in organic solvents and well-controlled in chain length. Recently, Hirao reported that the use of a DPE anion as the initiator in the presence of a $10 \sim 20$ fold excess of lithium halides $(\mathrm{LiCl}$ or $\mathrm{LiBr})$ is effective to further reduce the PDI value (PDI $=1.07-1.2$ ) of a similar polymer, PTVS, which could also be thermally converted to PA in $100 \%$ yield $[59,60]$. However, the addition of a large amount of salts in polymerization media requires a thorough drying process of the salts. In a macroinitiator system, this becomes quite a serious problem, because even a small amount of contamination from salts affords a mixture of a deactivated homopolymer with the expected BCP. Therefore, a new living system has to be developed, especially suited for the macroinitiator system.

To prepare the $\alpha, \omega$-difunctional P3HT macroinitiator, if a precursory DPE difunctional P3HT (DPE-P3HT-DPE) is reacted with a large excess of sec-butyllithium (sec-BuLi) toward the DPE moieties, the expected macroinitiator can be obtained by an addition reaction of sec-BuLi with the terminal DPE moieties, leaving an excess of sec-BuLi. However, sec-BuLi can selectively decompose with a THF solvent into ethylene gas and lithium enolate by elevating the temperature to $25{ }^{\circ} \mathrm{C}$ (Scheme 3) [17]. It should be noted that stabler initiating DPE anions survive under this condition and the generated ethylene and lithium enolate are inert in the living polymerization [17]. We expected that the in situ-generated lithium enolate would function to lower the PDI of PTVS instead of the lithium halides.

A model homopolymerization of TVS was carried out in THF initiated by 3-methyl-1,1-diphenylpentyllithium in the presence of lithium enolate, derived from DPE and a large excess of sec-BuLi (Scheme 4). The results are summarized in Table 1. The molecular weight ranges from 5,200 to 27,000 with low PDI (1.10-1.22), as expected. The representative SEC profile is shown 
in Figure 1. In a blank experiment, the PDI increases to around 1.5 without lithium enolate. Consequently, the in situ-generated salt, lithium enolate, is found to be effective to obtain PTVS with controlled MWs and low PDIs.

Scheme 3. Preparation of $\alpha, \omega$-difunctional P3HT macroinitiator.
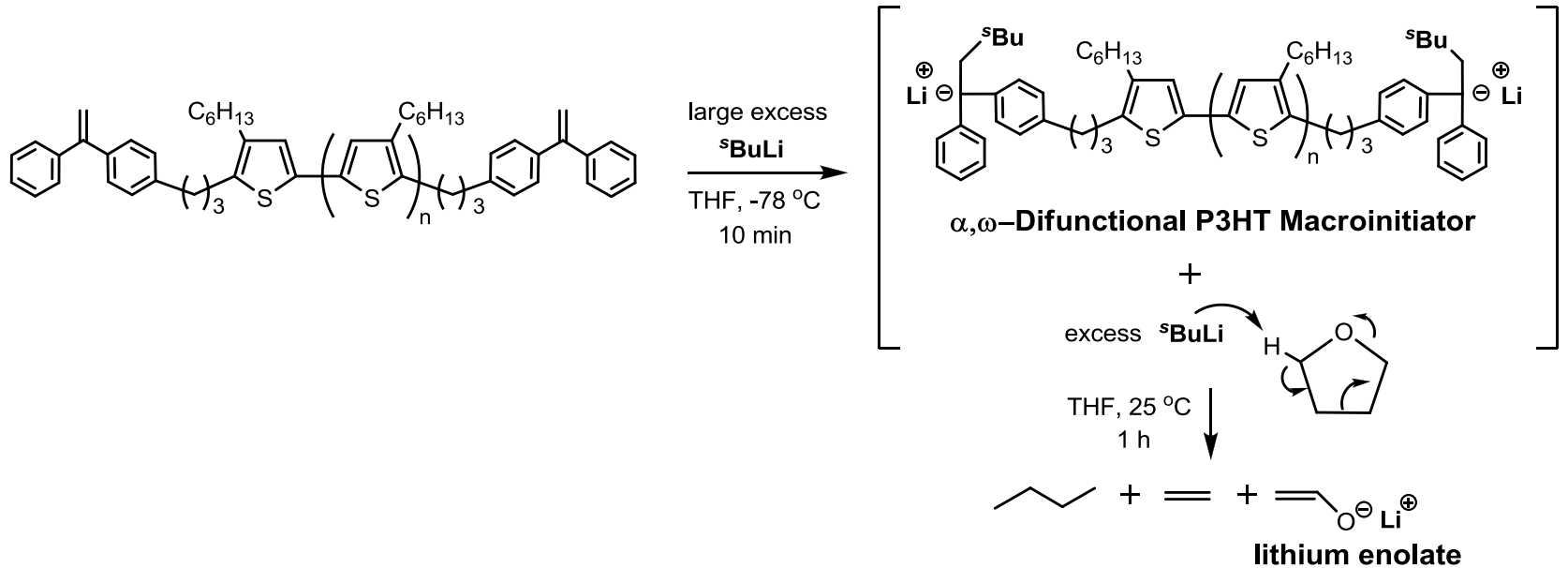

Scheme 4. Homopolymerziation of TVS initiated by 3-methyl-1,1-diphenylpentyllithium in the presence of lithium enolate.

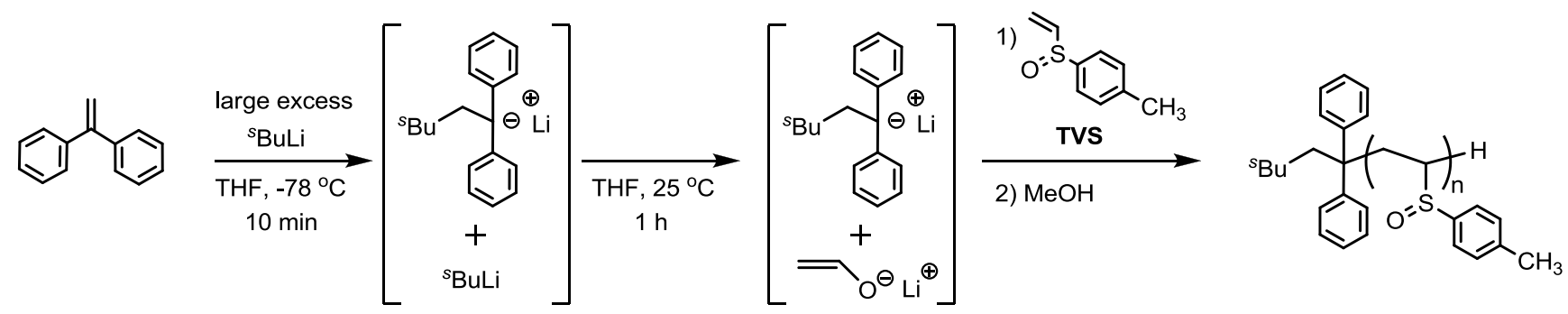

Table 1. Living anionic polymerization of TVS initiated by 3-methyl-1,1diphenylpentyllithium in THF at $-78{ }^{\circ} \mathrm{C}^{a}$.

\begin{tabular}{|c|c|c|c|c|c|}
\hline \multirow[t]{2}{*}{ [lithium enolate]/[DPE] } & \multirow[t]{2}{*}{$D P_{\mathrm{n}}^{b}$} & \multicolumn{3}{|c|}{$M_{\mathrm{n}}(\mathrm{g} / \mathrm{mol})$} & \multirow[t]{2}{*}{ PDI } \\
\hline & & calcd $^{b}$ & GPC-RALLS & ${ }^{1} \mathbf{H ~ N M R}^{c}$ & \\
\hline 20 & 30 & 5,220 & 5,200 & 5,320 & 1.10 \\
\hline 17 & 56 & 9,690 & 9,860 & $8,690^{d}$ & 1.18 \\
\hline 19 & 150 & 25,200 & 27,000 & - & 1.22 \\
\hline 0 & 60 & 10,200 & 8,600 & 9,300 & 1.54 \\
\hline
\end{tabular}

${ }^{a}$ Yields of polymers are always more than $99 \% .{ }^{b}$ Calculated from feed ratio of initiator and monomer.

${ }^{c}$ Calculated from signal intensities assignable to 6 methyl protons of sec-butyl group (0.6-0.8 ppm) and aromatic protons of main chains $(7.0-8.0 \mathrm{ppm}) .{ }^{d} 1,1-\mathrm{Bis}$ (4-trimethylsilylphenyl)ethylene was used instead of DPE for more accurate calculation of MWs by ${ }^{1} \mathrm{H}$ NMR spectrum, showing a sharp signal assignable to trimethylsilyl terminal units at $0.2-0.3 \mathrm{ppm}$. The MWs were calculated from the signal intensities assignable to 18 protons of the trimethylsilyl group $(0.2-0.3 \mathrm{ppm})$ and aromatic protons of the main chains $(7.0-8.0 \mathrm{ppm})$. 
Figure 1. SEC RI trace of PTVS homopolymer.

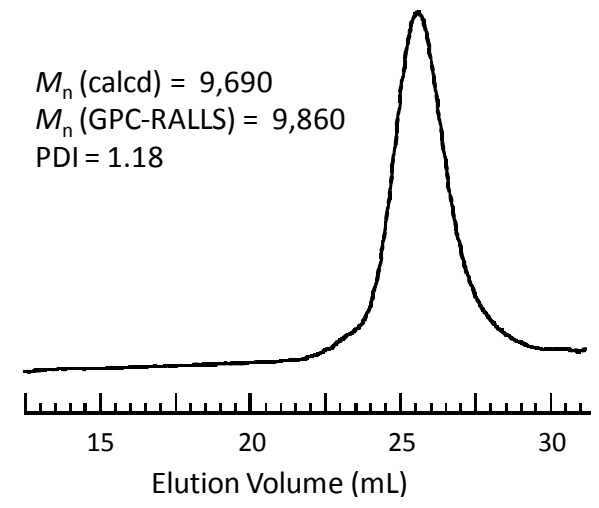

\subsection{Synthesis of PTVS-b-P3HT-b-PTVS}

To synthesize PTVS- $b$-P3HT- $b$-PTVS, precursory DPE difunctional P3HT (DPE-P3HT-DPE, $M_{\mathrm{n}}=12,500, \mathrm{PDI}=1.10$, r.r. $\left.=97 \%\right)$ was reacted with a 20 -fold excess of $s e c$-butyllithium $($ sec-BuLi $)$ toward the DPE moieties in THF at $-78^{\circ} \mathrm{C}$ for $10 \mathrm{~min}$. The excess sec-BuLi decomposed with THF by warming to room temperature and keeping for $1 \mathrm{~h}$, resulting in in situ generation of excess lithium enolate. The system was then cooled back to $-78{ }^{\circ} \mathrm{C}$. TVS was next added at $-78{ }^{\circ} \mathrm{C}$ to start the living anionic polymerization, followed by quenching with degassed methanol (Scheme 2). As shown in the SEC chromatograms (Figure 2), the peak top for the precursory DPE-P3HT-DPE obviously shifts to a higher molecular weight region after the polymerization. Unfortunately, there is a minor shoulder corresponding to unreacted DPE-P3HT-DPE, probably because of incomplete initiation from the partially aggregated macroinitiator in THF at $-78{ }^{\circ} \mathrm{C}$, similar to the case in the synthesis of PMMA- $b$ P3HT- $b$-PMMA [17]. Eventually, it was successfully eliminated from the mixture by fractional precipitation using ethyl acetate. The isolated PTVS- $b$-P3HT- $b$-PTVS possesses a unimodal sharp peak (Figure 2). The $M_{\mathrm{n}}$ value of PTVS- $b$-P3HT- $b$-PTVS, determined by SEC-RALLS $(24,500)$, is in good agreement with the calculated one (22,300). The PDI value determined by SEC is acceptable (1.33).

Figure 2. SEC RI traces of (A) DPE-P3HT-DPE, (B) the crude product, and (C) the isolated PTVS- $b$-P3HT- $b$-PTVS.

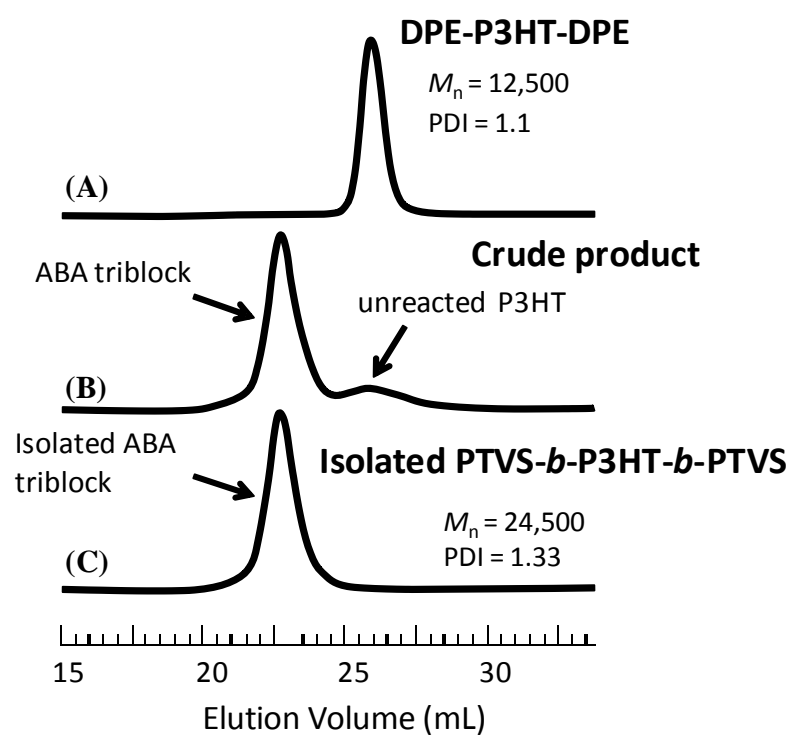


Moreover, ${ }^{1} \mathrm{H}$ NMR spectroscopy of PTVS- $b$-P3HT- $b$-PTVS confirms the absence of a signal for the vinyl protons of the DPE moieties at $5.4 \mathrm{ppm}$, as well as a reasonable composition of two segments being almost consistent with that targeted (Figure 3(B)). Thus, the expected PTVS- $b$-P3HT- $b$-PTVS $(6,000-12,500-6,000)$ could be successfully synthesized. It should be noted that the DPE chemistry employed here is quite elegant and efficient for designing a wide range of well-defined BCPs, because the 1,1-diphenylalkyl anion is able to undergo living anionic polymerization of many other kinds of monomers, acrylates, acryl amides, vinylpyridines, epoxides, propylene sulfide, and so on.

Figure 3. ${ }^{1} \mathrm{H}$ NMR spectra of (A) DPE-P3HT-DPE and (B) PTVS- $b$-P3HT- $b$-PTVS.

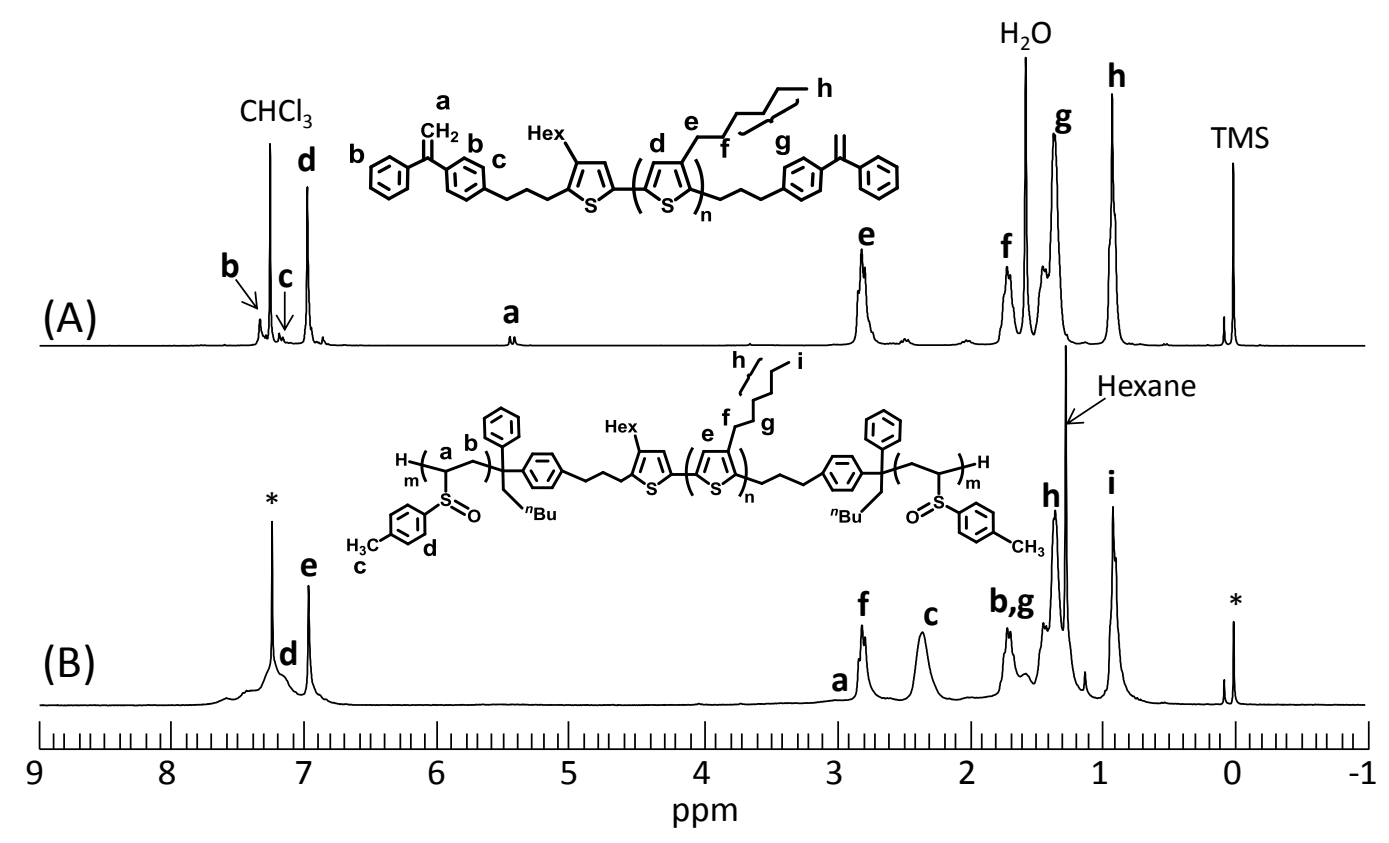

\subsection{Synthesis of $P A-\mathrm{b}-P 3 H T-\mathrm{b}-P A$}

The transformation from PTVS- $b$-P3HT- $b$-PTVS into PA- $b$-P3HT- $b$-PA was performed simply by thermal treatment at $170{ }^{\circ} \mathrm{C}$ for $2 \mathrm{~h}$ under vacuum (Scheme 2). Figure 4(A) shows the TGA curve of PTVS- $b$-P3HT- $b$-PTVS. The first weight-loss from 120 to $250{ }^{\circ} \mathrm{C}$ may be ascribed to the elimination of 4-tolylsulfenic acid from the PTVS segments, as confirmed by the weight-loss behavior of a PTVS homopolymer (Figure 4(B)). The weight loss percentage at temperatures in the range of 120 to $250{ }^{\circ} \mathrm{C}$ was nearly consistent with that assumed by complete elimination. The second weight-loss was seen from 350 to $470{ }^{\circ} \mathrm{C}$, corresponding to the degradation of the PA- $b$-P3HT- $b$-PA segments.

The FT-IR spectrum of PTVS- $b$-P3HT- $b$-PTVS (Figure 5(A)) showed a strong absorption band at $1,045 \mathrm{~cm}^{-1}$, assignable to $\mathrm{S}=\mathrm{O}$ stretching, which completely disappeared after thermal treatment. Instead, an absorption band at $1,005 \mathrm{~cm}^{-1}$, attributed to trans-vinylene out-of-plane deformation from PA main chains, newly appeared (Figure 5(B)). In addition, the polymer became insoluble in common organic solvents, while precursory PTVS- $b$-P3HT- $b$-PTVS was well soluble in toluene, chloroform, and THF.

These analytical results clearly confirmed the complete conversion from PTVS to PA chains by quantitatively eliminating 4-tolylsulfenic acid in PTVS- $b$-P3HT- $b$-PTVS. 
Figure 4. TGA thermograms of (A) PTVS- $b$-P3HT- $b$-PTVS and (B) PTVS homopolymer.

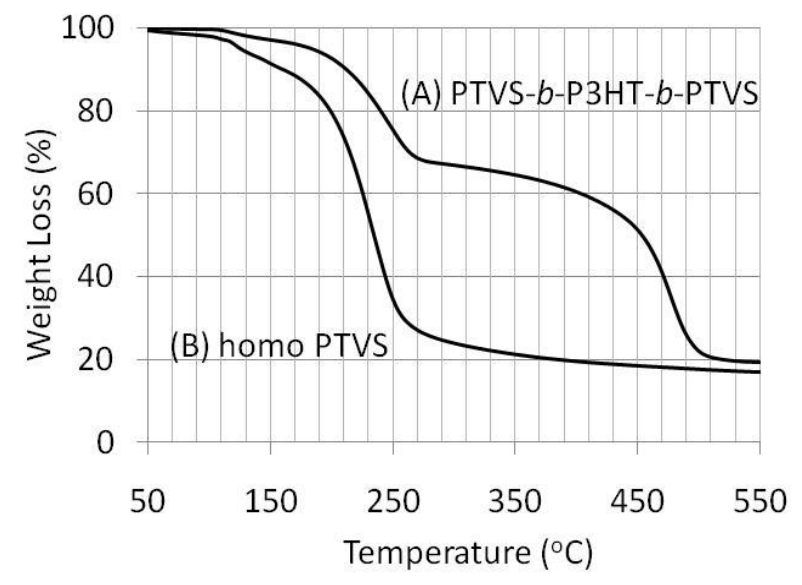

Figure 5. IR spectra of (A) PTVS- $b$-P3HT- $b$-PTVS and (B) PA- $b$-P3HT- $b$-PA.

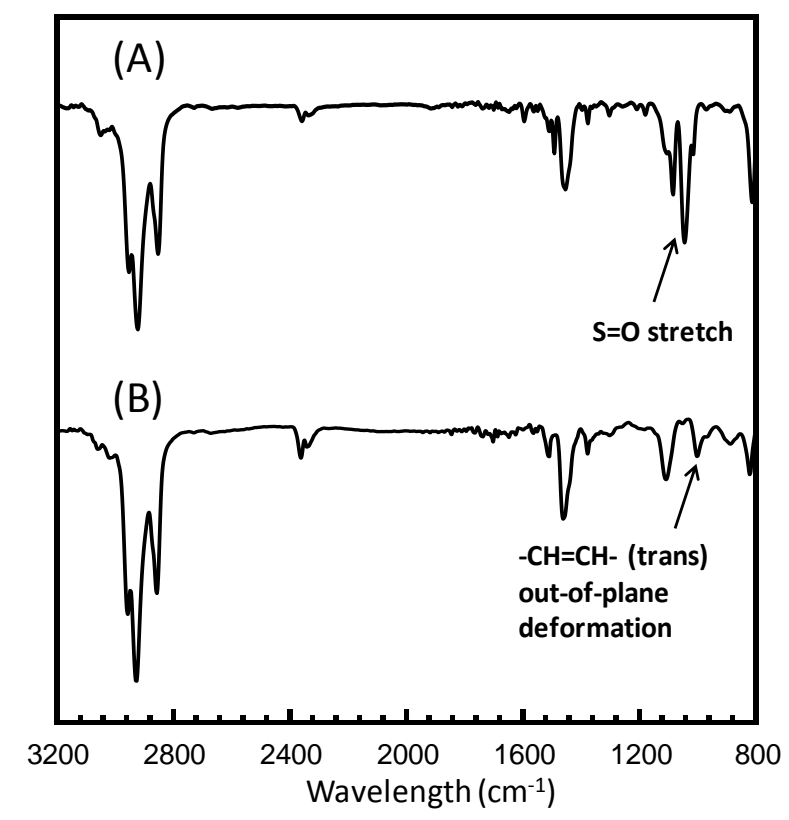

\subsection{Optical and Electronic Properties}

The optical property of PTVS- $b$-P3HT- $b$-PTVS was studied by UV-vis spectroscopy. The solution-state UV-vis spectrum of PTVS- $b$-P3HT- $b$-PTVS in chloroform showed maximum absorption $\left(\lambda_{\max }\right)$ for the $\pi-\pi *$ transition of the P3HT inner segment at around $442 \mathrm{~nm}$ (Figure 6 (yellow line)). In the film state, the $\lambda_{\max }$ value of the polymer was bathochromically shifted to around $565 \mathrm{~nm}$ compared with that in the solution state (pink line). In addition, the polymer showed a shoulder at around $610 \mathrm{~nm}$ related to vibronic absorption, similar to the pristine P3HT film (purple line). This observation indicates a high degree of ordering in the polymer films even if PTVS is covalently linked to P3HT. After thermal transformation, the absorbance was somewhat red-shifted to obtain an off-set value at a longer wavelength $(\sim 700 \mathrm{~nm}$, green line)). This indicates the successful conversion from PTVS to PA segments in the PTVS- $b$-P3HT- $b$-PTVS film. Interestingly, even after generating a highly rigid-rod PA segment, the shoulder at around $610 \mathrm{~nm}$ remains intact, indicative of highly ordered P3HT packing 
structures. Therefore, the thermal transformation reaction seems not to destroy the self-assembled structures, derived from precursory PTVS- $b$-P3HT- $b$-PTVS in the film state.

Figure 6. UV-vis spectra of PTVS- $b$-P3HT- $b$-PTVS in chloroform (yellow line), PTVS- $b$-P3HT- $b$-PTVS film (yellow line), PA- $b$-P3HT- $b$-PA (green line), and P3HT film (purple line).

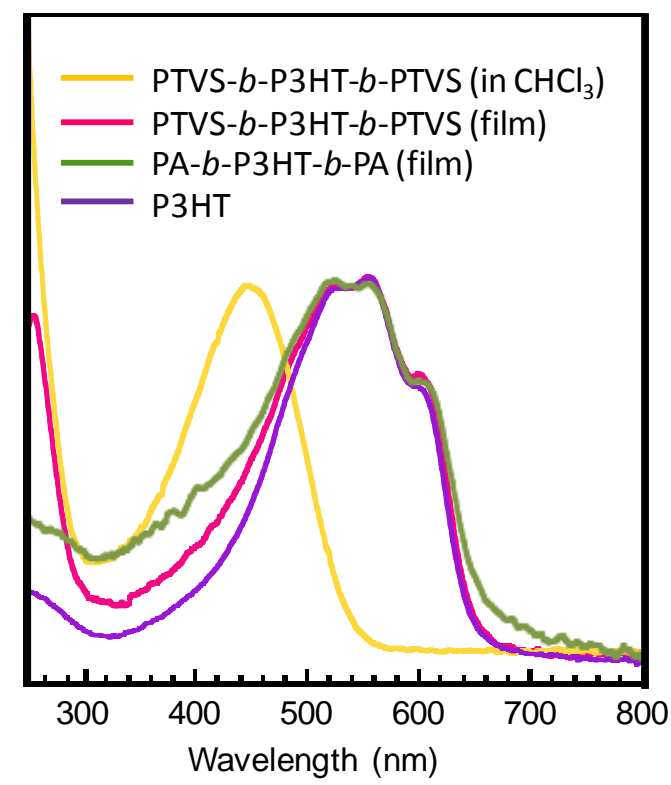

Electrical conductivity of PA- $b$-P3HT- $b$-PA was then measured by using a typical four-point probe technique. After iodine doping, relatively high conductivity of $0.126 \mathrm{~S} / \mathrm{cm}$ was obtained, while overflow resistance was obtained for an undoped sample of PA- $b$-P3HT- $b$-PA. In order to improve the conductivity to more than $10 \mathrm{~S} / \mathrm{cm}$, a film-forming condition to obtain nanofibril or nanowire structures may be required [61].

\subsection{AFM Images of Block Copolymers}

To gain insight into the morphology, a thin film of PTVS- $b$-P3HT- $b$-PTVS was prepared by drop casting from a toluene solution onto a mica substrate at room temperature. The film thickness was estimated to be $100 \mathrm{~nm}$ by Dektak ${ }^{3}$. Figure 7(A) and 7(B) show tapping-mode AFM height and phase images of the PTVS- $b$-P3HT- $b$-PTVS thin film surface, respectively, after solvent annealing with toluene vapor at room temperature for $3 \mathrm{~h}$. Although a periodic microphase-separated morphology is not observed, continuous nanofibril structures are observed at 10-20 nm sizes in whole areas, without macrophase separation or large aggregation. Figure 7(C) and 7(D) show tapping-mode AFM height and phase images of the PA- $b$-P3HT- $b$-PA thin film obtained by a thermal transformation reaction of PTVS- $b$-P3HT- $b$-PTVS on a mica substrate. As can be seen, there is almost no difference in morphology before and after the transformation, which might be coincident with the observation by UV-vis spectroscopy showing a high degree of ordering in P3HT packing even after the thermal transformation. In contrast, the roughness determined by height images significantly changed after the transformation from 6.5 to $17.6 \mathrm{~nm}$. This result suggests that the PA- $b$-P3HT- $b$-PA film possesses 
discrete pits [22] in the matrix on a nano-scale, probably generated by eliminating $c a$. $85 \mathrm{vol} \%$ of a large leaving group, 4-tolylsulfenic acid, from PTVS domains, which are anchored by rigid and crystalline P3HT domains in the film state. Such semiconducting nanoporous films are quite interesting materials, especially for solar cell device applications [62], after back-fill of $n$-type semiconductors into nanoporous matrices, possibly achieving large $p / n$ interface areas with controlled morphological domain widths which correspond to exciton diffusion lengths.

Figure 7. Tapping-mode AFM images of the thin film surfaces of PTVS- $b$-P3HT- $b$-PTVS (A: height image, B: phase image) and PA- $b$-P3HT- $b$-PA (C: height image, D: phase image).

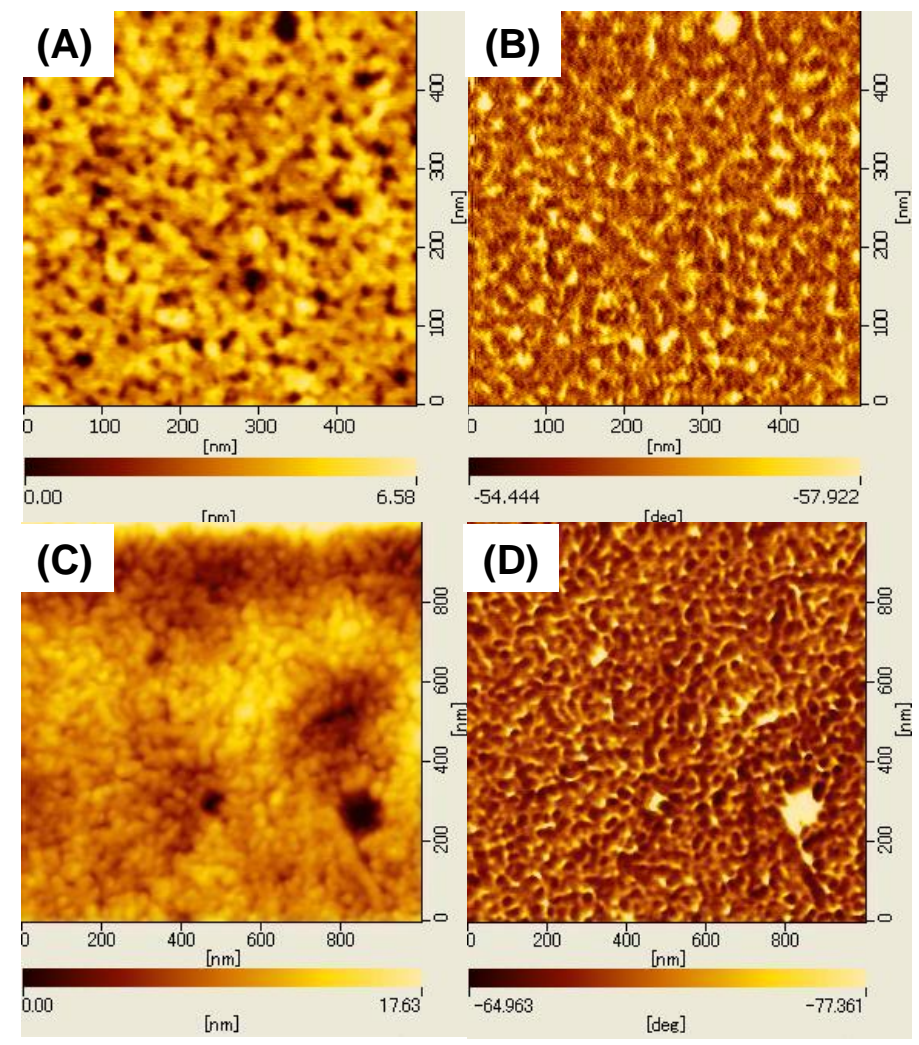

\section{Conclusions}

Living anionic polymerization of TVS in THF at $-78{ }^{\circ} \mathrm{C}$, initiated with a DPE anion as the initiator, has been achieved in the presence of in situ-generated lithium enolate. The MWs of PTVS was controlled from 5,200 to 27,000 with relatively low PDI (1.10-1.22). Based on these results, PTVS- $b$-P3HT- $b$-PTVS (6,000-12,500-6,000) could be successfully synthesized using a P3HT-based difunctional macroinitiator with two DPE anions at both chain ends in the presence of lithium enolate. The high degree of structural homogeneity of the BCP was confirmed by GPC-RALLS and ${ }^{1} \mathrm{H}$ NMR. The thermal transformation from PTVS- $b$-P3HT- $b$-PTVS to PA- $b$-P3HT- $b$-PA was quantitative, as monitored by TGA and FT-IR analyses. The synthesized rod-rod-rod type triblock copolymer, PA- $b$-P3HT- $b$-PA, has never been reported before. The optical and electronic properties of BCPs were investigated by UV-vis spectroscopy and conductivity measurement, respectively. Finally, tapping mode AFM images of PTVS- $b$-P3HT- $b$-PTVS and PA- $b$-P3HT- $b$-PA thin film surfaces showed continuous nanofibril structures. In particular, AFM height images of those surfaces suggest the creation of nanoporous structures in the PA- $b$-P3HT- $b$-PA film. 


\section{Acknowledgements}

We would like to thank the Japan Society for the Promotion of Science (JSPS), KAKENHI (20850014), as well as the Noguchi institute, Noguchi foundation, for supporting this work.

\section{References}

1. Scherf, U.; Gutacker, A.; Koenen, N.All-conjugated block copolymers. Acc. Chem. Res. 2008, 41, 1086-1097.

2. Lee, M.; Cho, B.K.; Zin, W.C. Supramolecular structures from rod-coil block copolymers. Chem. Rev. 2001, 101, 3869-3.

3. Di, C.-A.; Yu, C.; Liu, Y.-Q.; Zhu, D.-B. High-performance organic field-effect transistors: Molecular design, device fabrication, and physical properties. J. Phys. Chem. B 2007, 111, 14083-14096.

4. Kim, J.; Lee, Y.K.; Coates, N.E.; Moses, D.; Nguyen, T.-Q.; Dante, M.; Heeger, A.J. Efficient tandem polymer solar cells fabricated by all-solution processing. Science 2007, 317, 222-225.

5. Thompson, B.C.; Fréchet, J.M.J. Polymer-fullerene composite solar cells. Angew. Chem. Int. Ed. 2008, 47, 58-77.

6. Wei, Q.; Nishizawa, T.; Tajima, K.; Hashimoto, K. Self-organized buffer layers in organic solar cells. Adv. Mater. 2008, 20, 2211-2216.

7. Hempenius, M.A.; Langeveld-Voss, B.M.W.; van Haare, J.A.E.H.; Janssen, R.A.J.; Sheiko, S.S.; Spatz, J.P.; Moeller, M.; Meijer, E.W. Polystyrene-oligothiophene-polystyrene triblock copolymer. J. Am. Chem. Soc. 1998, 120, 2798-2804.

8. Iovu, M.C.; Sheina, E.E.; Gil, R.R.; McCullough, R.D. Experimental evidence for the quasi-"living" nature of the Grignard metathesis method for the synthesis of regioregular poly(3-alkylthiophenes). Macromolecules 2005, 38, 8649-8656.

9. Miyakoshi, R.; Yokoyama, A.; Yokozawa, T. Catalyst-transfer polycondensation. Mechanism of $\mathrm{Ni}$-catalyzed chain-growth polymerization leading to well-defined poly(3-hexylthiophene). J. Am. Chem. Soc. 2005, 127, 17542-17547.

10. Jeffries-El, M.; Sauvé, G.; McCullough, R.D. In-situ end-group functionalization of regioregular poly(3-alkylthiophene) using the Grignard metathesis polymerization method. Adv. Mater. 2004, 16, 1017-1019.

11. Jeffries-El, M.; Sauvé, G.; McCullough, R.D. Facile synthesis of end-functionalized regioregular poly(3-alkylthiophene)s via modified Grignard metathesis reaction. Macromolecules 2005, 38, 10346-10352.

12. Iovu, M.C.; Jeffries-EL, M.E.; Sheina, E.; Cooper, J.R.; McCullough, R.D. Regioregular poly(3-alkylthiophene) conducting block copolymers. Polymer 2005, 46, 8582-8586.

13. Radano, C.P.; Scherman, O. A.; Stingelin-Stutzmann, N.; Mueller, C.; Breiby, D.W.; Smith, P.; Janssen, R.A.J.; Meijer, E.W. Crystalline-crystalline block copolymers of regioregular poly(3-hexylthiophene) and polyethylene by ring-opening metathesis polymerization. J. Am. Chem. Soc. 2005, 127, 12502-12503. 
14. Iovu, M.C.; Craley, C.R.; Jeffries-EL, M.; Krankowski, A.B.; Zhang, R.; Kowalewski, T.; McCullough, R.D. Conducting regioregular polythiophene block copolymer nanofibrils synthesized by reversible addition fragmentation chain transfer polymerization (RAFT) and nitroxide mediated polymerization (NMP). Macromolecules 2007, 40, 4733-4735.

15. Dai, C.-A.; Yen, W.-C.; Lee, Y.-H.; Ho, C.-C.; Su, W.-F. Facile synthesis of well-defined block copolymers containing regioregular poly(3-hexylthiophene) via anionic macroinitiation method and their self-assembly behavior. J. Am. Chem. Soc. 2007, 129, 11036-11038.

16. Higashihara, T.; Ohshimizu, K.; Hirao, A.; Ueda, M. Facile synthesis of ABA triblock copolymer containing regioregular poly(3-hexylthiophene) and polystyrene segments via linking reaction of poly(styryl)lithium. Macromolecules 2008, 41, 9505-9507.

17. Higashihara, T.; Ueda, M. Synthesis and characterization of a novel coil-rod-coil triblock copolymers comprised of regioregular poly(3-hexylthiophene) and poly(methyl methacrylate) segments. React. Funct. Polym. 2009, 69, 457-462.

18. Higashihara, T.; Ueda, M. Living anionic polymerization of 4-vinyltriphenylamine for synthesis of novel block copolymers containing low-polydisperse poly(4-vinyltriphenylamine) and regioregular poly(3-hexylthiophene) segments. Macromolecules 2009, 42, 8794-8800.

19. Higashihara, T.; Takahashi, A.; Tajima, S.; Jin, S.; Rho, Y.; Ree, M.; Ueda, M. Synthesis of block copolymers consisting of poly(3-hexylthiophene) and polystyrene segments through ionic interaction and their self-assembly behavior. Polym. J. 2010, 42, 43-50.

20. Takahashi, A.; Rho, Y.; Higashihara, T.; Ahn, B.; Ree, M.; Ueda, M. Preparation of nanoporous poly(3-hexylthiophene) films based on a template system of block copolymers via ionic interaction. Macromolecules 2010, 43, 4843-4852.

21. Tsai, J.-H.; Lai, Y.-C.; Higashihara, T.; Lin, C.-J.; Ueda, M.; Chen, W.-C. Enhancement of P3HT/PCBM photovoltaic efficiency using the surfactant of triblock copolymer containing poly(3-hexylthiophene) and poly(4-vinyltriphenylamine) segments. Macromolecules 2010, 43, 6085-6091.

22. Boudouris, B.W.; Frisbie, C.D.; Hillmyer, M.A. Nanoporous poly(3-alkylthiophene) thin films generated from block copolymer templates. Macromolecules 2008, 41, 67-75.

23. Boudouris, B.W.; Frisbie, C.D.; Hillmyer, M.A. Polylactide-polythiophene-polylactide triblock copolymers. Macromolecules 2010, 43, 3566-3569.

24. Urien, M.; Erothu, H.; Cloutet, E.; Hiorns, R.C.; Vignau, L.; Cramail, H. Poly(3-hexylthiophene) based block copolymers prepared by Click chemistry. Macromolecules 2008, 41, 7033-7040.

25. Richard, F.; Brochon, C.; Leclerc, N.; Eckhardt, D.; Heiser T.; Hadziioannou, G. Design of a linear poly(3-hexylthiophene)/fullerene-based donor-acceptor rod-coil block copolymer. Macromol. Rapid Commun. 2008, 29, 885-891.

26. Sommer, M.; Lang, A.S.; Thelakkat, M. Crystalline-crystalline donor-acceptor block copolymers. Angew. Chem., Int. Ed. 2008, 47, 7901-7904.

27 Craley, C.R.; Zhang, R.; Kowalewski, T.; McCullough, R.D.; Stefan, M. Regioregular poly(3-hexylthiophene) in a novel conducting amphiphilic block copolymer. Macromol. Rapid Commun. 2009, 30, 11-16.

28 Zou, J.; Khondaker, S.I.; Huo, Q.; Zhai, L. A general strategy to disperse and functionalize carbon nanotubes using conjugated block copolymers. Adv. Funct. Mater. 2009, 19, 479-483. 
29. Lee, J.U.; Cirpan, A.; Emrick, T.; Russell, T.P.; Jo, W.H. Synthesis and photophysical property of well-defined donor-acceptor diblock copolymer based on regioregular poly(3-hexylthiophene) and fullerene. J. Mater. Chem. 2009, 19, 1483-1489.

30. Yang, C.; Lee, J.K.; Heeger, A.J.; Wudl, F. Well-defined donor-acceptor rod-coil diblock copolymers based on P3HT containing C60: The morphology and role as a surfactant in bulk-heterojunction solar cells. J. Mater. Chem. 2009, 19, 5416-5423.

31. Zhang, Q.; Cirpan, A.; Russell, T.P.; Emrick, T. Donor-acceptor poly(thiophene-block-perylene diimide) copolymers: Synthesis and solar cell fabrication. Macromolecules 2009, 42, 1079-1082.

32. Tao, Y.; McCulloch, B.; Kim, S.; Segalman, R.A. The relationship between morphology and performance of donor-acceptor rod-coil block copolymer solar cells. Soft Matter 2009, 5, 4219-4230.

33. Alemseghed, M.G.; Gowrisanker, S.; Servello, J.; Stefan, M.C. Synthesis of di-block copolymers containing regioregular poly(3-hexylthiophene) and poly(tetrahydrofuran) by a combination of Grignard metathesis and cationic polymerizations. Macromol. Chem. Phys. 2009, 210, 2007-2014.

34. Alemseghed, M.G.; Servello, J.; Hundt, N.; Sista, P.; Biewer, M.C.; Stefan, M.C. Amphiphilic block copolymers containing regioregular poly(3-hexylthiophene) and poly(2-ethyl-2-oxazoline). Macromol. Chem. Phys. 2010, 211, 1291-1297.

35. Moon, H.C.; Anthonysamy, A.; Lee, Y.; Kim, J.K. Facile synthesis of well-defined coil-rod-coil block copolymer composed of regioregular poly(3-hexylthiophene) via anionic coupling reaction. Macromolecules 2010, 43, 1747-1752.

36. Lim, H.; Huang, K.-T.; Su, W.-F.; Chao, C.-Y. Facile syntheses, morphologies, and optical absorptions of P3HT coil-rod-coil triblock copolymers. J. Polym. Sci. A Polym. Chem. 2010, 48, 3311-3322.

37. Kaul, E.; Senkovskyy, V.; Tkachov, R.; Bocharova, V.; Komber, H.; Stamm, M.; Kiriy, A. Synthesis of a bifunctional initiator for controlled Kumada catalyst-transfer polycondensation/nitroxide-mediated polymerization and preparation of poly(3-hexylthiophene)polystyrene block copolymer therefrom. Macromolecules 2010, 43, 77-81.

38. Surin, M.; Coulembier, O.; Tran, K.; De Winter, J.; Leclere, P.; Gerbaux, P.; Lazzaroni, R.; Dubois, P. Regioregular poly(3-hexylthiophene)-poly( $\varepsilon$-caprolactone) block copolymers: Controlled synthesis, microscopic morphology, and charge transport properties. Org. Elect. 2010, 11, 767-774.

39. Park, S.-J.; Kang, S.-G.; Fryd, M.; Saven, J.G.; Park, S.-J. Highly tunable photoluminescent properties of amphiphilic conjugated block copolymers. J. Am. Chem. Soc. 2010, 132, 9931-9933.

40. Wu, Z.-Q.; Ono, R.J.; Chen, Z.; Bielawski, C.W. Synthesis of poly(3-alkylthiophene)-blockpoly(arylisocyanide): Two sequential, mechanistically distinct polymerizations using a single catalyst. J. Am. Chem. Soc. 2010, 132, 14000-14001.

41. Yokozawa, T.; Adachi, I.; Miyakoshi, R.; Yokoyama, A. Catalyst-transfer condensation polymerization for the synthesis of well-defined polythiophene with hydrophilic side chain and of diblock copolythiophene with hydrophilic and hydrophobic side chains. High Perform. Polym. 2007, 19, 684-699.

42. Ohshimizu, K.; Ueda, M. Well-controlled synthesis of block copolythiophenes. Macromolecules 2008, 41, 5289-5294. 
43. Chueh, C.C.; Higashihara, T.; Tsai, J.-H.; Ueda, M.; Chen, W.-C. All-conjugated diblock copolymer of poly(3-hexylthiophene)-block-poly(3-phenoxymethylthiophene) for field-effect transistor and photovoltaic applications. Org. Electron. 2009, 10, 1541-1548.

44. Zhang, Y.; Tajima, K.; Hirota, K.; Hashimoto, K. Synthesis of all-conjugated diblock copolymers by quasi-living polymerization and observation of their microphase separation. J. Am. Chem. Soc. 2008, 130, 7812-7813.

45. Benanti, T.L.; Kalaydjian, A.; Venkataraman, D. Protocols for efficient postpolymerization functionalization of regioregular polythiophenes. Macromolecules 2008, 41, 8312-8315.

46. Ouhib, F.; Khoukh, A.; Ledeuil, J.-B.; Martinez, H.; Desbrires, J.; Dagron-Lartigau, C. Diblock and random donor/acceptor "double cable" polythiophene copolymers via the GRIM method. Macromolecules 2008, 41, 9736-9743.

47. van den Bergh, K.; Huybrechts, J.; Verbiest, T.; Koeckelberghs, G. Transfer of supramolecular chirality in block copoly(thiophene)s. Chem. Eur. J. 2008, 14, 9122-9125.

48. Ouhib, F.; Hiorns, R.C.; de Bettignies, R.; Bailly, S.; Desbrières, J.; Dagron-Lartigau, C. Photovoltaic cells based on polythiophenes carrying lateral phenyl groups. Thin Sol. Films 2008 , 516, 7199-7204.

49. Wu, P.-T.; Ren, G.; Li, C.; Mezzenga, R.; Jenekhe, S.A. Crystalline diblock conjugated copolymers: Synthesis, self-assembly, and microphase separation of poly(3-butylthiophene)- $b$ poly(3-octylthiophene). Macromolecules 2009, 42, 2317-2320.

50. Wu, P.-T.; Ren, G.; Kim, F.S.; Li, C.; Mezzenga, R.; Jenekhe, S.A. Poly(3-hexylthiophene)-bpoly(3-cyclohexylthiophene): Synthesis, microphase separation, thin film transistors, and photovoltaic applications. J. Polym. Sci. A Polym. Chem. 2010, 48, 614-626.

51. He, M.; Zhao, L.; Wang, J.; Han, W.; Yang, Y.; Qiu, F.; Lin, Z. Self-assembly of all-conjugated poly(3-alkylthiophene) diblock copolymer nanostructures from mixed selective solvents. ACS Nano 2010, 4, 3241-3247.

52. Hollinger, J.; Jahnke, A.A.; Coombs, N.; Seferos, D.S. Controlling phase separation and pptical properties in conjugated polymers through selenophene-thiophene copolymerization. J. Am. Chem. Soc. 2010, 132, 8546-8547.

53. Miyakoshi, R.; Yokoyama, A.; Yokozawa, T. Importance of the order of successive catalyst-transfer condensation polymerization in the synthesis of block copolymers of polythiophene and poly (p-phenylene). Chem. Lett. 2008, 37, 1022-1023.

54. Javier, A.E.; Varshney, S.R.; McCullough, R.D. Chain-growth synthesis of polyfluorenes with low polydispersities, block bopolymers of fluorene, and end-capped polyfluorenes: Toward new optoelectronic materials. Macromolecules 2010, 43, 3233-3237.

55. Shirakawa, H.; Louis, E.J.; MacDiarmid, A.G.; Chiang, C.K.; Heeger, A.J. Synthesis of electrically conducting organic polymers: halogen derivatives of polyacetylene, $(\mathrm{CH}) x . J$. Chem. Soc. Chem. Commun. 1977, 16, 578-580.

56. Simionescu, C.I.; Percec, V. Progress in polyacetylene chemistry. Prog. Polym. Sci. 1982, 8, 133-214.

57. Akagi, K. Helical polyacetylene: Asymmetric polymerization in a chiral liquid-crystal field. Chem. Rev. 2009, 109, 5354-5401. 
58. Kanga, R.S.; Hogen-Esch, T.E.; Randrianalimanana, E.; Soum, A.; Fontanille, M. Studies of the anionic polymerization of phenylvinylsulfoxide and its copolymer with styrene. Macromolecules 1990, 23, 4235-4240.

59. Zhao, Y.; Higashihara, T.; Sugiyama, K.; Hirao, A. Synthesis of functionalized asymmetric star polymers containing conductive polyacetylene segments by living anionic polymerization. J. Am. Chem. Soc. 2005, 127, 14158-14159.

60. Zhao, Y.; Higashihara, T.; Sugiyama, K.; Hirao, A. Synthesis of asymmetric star-branched polymers having two polyacetylene arms by means of living anionic polymerization using 1,1-diphenylethylene derivatives. Macromolecules 2007, 40, 228-238.

61. Iovu, M.C.; Craley, C.R.; Jeffries-EL, M.; Krankowski, A.B.; Zhang, R.; Kowalewski, T.; McCullough, R.D. Conducting regioregular polythiophene block copolymer nanofibrils synthesized by reversible addition fragmentation chain transfer polymerization (RAFT) and nitroxide mediated polymerization (NMP). Macromolecules 2007, 40, 4733-4735.

62. Kim, J.S.; Park, Y.; Lee, D.Y.; Lee, J.H.; Park, J.H.; Kim, J.K.; Cho, K. Poly(3-hexylthiophene) nanorods with aligned chain orientation for organic photovoltaics. Adv. Funct. Mater. 2010, 20, 540-545.

(C) 2011 by the authors; licensee MDPI, Basel, Switzerland. This article is an open access article distributed under the terms and conditions of the Creative Commons Attribution license (http://creativecommons.org/licenses/by/3.0/). 